\title{
Exclusive breastfeeding and associated factors among mothers in Gozamin district, northwest Ethiopia: a community based cross-sectional study
}

Melkamu Tamir Hunegnaw ${ }^{1 *}$, Lemma Derseh Gezie² and Alemayehu Shimeka Teferra²

\begin{abstract}
Background: Exclusive breastfeeding is defined as feeding infants only breast milk, be it directly from breast or expressed, except drops or syrups consisting of vitamins, mineral supplements or medicine. Exclusive breastfeeding is one of the essential actions for infant development and survival. However, the prevalence of exclusive breastfeeding in Ethiopia has been estimated at 52\% which is far less than the World Health Organization (WHO) recommendations. Moreover, there are inconsistencies among estimates in different districts of the country. Therefore, this study aimed to assess the prevalence and associated factors of exclusive breastfeeding among mothers in Gozamin district, northwest Ethiopia.
\end{abstract}

Methods: Using the simple random sampling technique, seven kebeles (lowest administrative units) were selected as the primary sampling unit of the district. Sample mother-infant pairs were then selected using the systematic random sampling technique that involved our moving from house to house in each village. Data were collected from 506 mother-infant pairs using interviews. Factors associated with exclusive breastfeeding were determined using logistic regression. The measure of association used was the odds ratio, and statistical tests with $p$-values of less than 0.05 were considered as statistically significant.

Results: In this study, the prevalence of exclusive breastfeeding among mothers was $74.1 \%$ (95\% Cl 70.80, 79.10). For government employee mothers, the odds of exclusive breastfeeding were reduced by half compared to housewives (AOR 0.49, 95\% Cl 0.26, 0.94). Mothers who did not receive breastfeeding counseling after delivery were 0.43 times less likely to practice exclusive breastfeeding compared with mothers who received the services (AOR $0.43,95 \% \mathrm{Cl} 0.25,0.72$ ). Mothers who gave birth at health institutions were more likely to practice exclusive breastfeeding.

Conclusion: Even though the estimated prevalence is relatively high, more effort to meet WHO recommendations is still necessary. Therefore, we suggest health institutions encourage hospital birthing and increase breastfeeding counseling after delivery, and employers needs to give longer maternity leave to improve exclusive breastfeeding practice.

Keywords: Exclusive breastfeeding, Gozamin district, Ethiopia

\footnotetext{
* Correspondence: mtamir082@gmail.com

1 Department of Human Nutrition, College of Medicine and Health Science,

University of Gondar, P.O Box, 196 Gondar, Ethiopia

Full list of author information is available at the end of the article
}

(c) The Author(s). 2017 Open Access This article is distributed under the terms of the Creative Commons Attribution 4.0 International License (http://creativecommons.org/licenses/by/4.0/), which permits unrestricted use, distribution, and reproduction in any medium, provided you give appropriate credit to the original author(s) and the source, provide a link to the Creative Commons license, and indicate if changes were made. The Creative Commons Public Domain Dedication waiver (http://creativecommons.org/publicdomain/zero/1.0/) applies to the data made available in this article, unless otherwise stated. 


\section{Background}

In order to achieve optimal growth, development and health, the World Health Organization (WHO) and the National Nutrition Programme (NNP) of Ethiopia recommend that infants should be exclusively breastfed for the first six months of life, which means that infants should receive only breast milk except prescribed medications, vitamins, and minerals $[1,2]$. The Government of Ethiopia strives to address under-nutrition through the Lifecycle Approach which includes ensuring that newborns are breastfed within one hour of birth and that exclusive breastfeeding (EBF) continue for the first six months, followed by adequate complementary feeding [2]. Breastfeeding has a significant role in improving nutrition, education, and maternal and child health [3].

Though studies showed that EBF has a potential to reduce under- five mortality by $11.6 \%$, the prevalence of EBF is still relatively low globally, as in sub Saharan Africa with a magnitude of $35 \%$ and $22-33 \%$, respectively [4]. According to WHO, 90\% EBF practice strongly reduces the incidence of infant mortality due to pneumonia [5]. The prevalence of EBF varied from country to country. For example, in Canada $10.4 \%$ of mothers exclusively breastfed [6], while in the Republic of Congo $2.8 \%$ did so [7]. On the contrary the prevalence of EBF was higher in developing countries than in developed ones, $49 \%$ in Timor, Asia, and $35.4 \%$ in Korea [8, 9].

Studies conducted on EBF in Ethiopia reported a variety of findings ranging from $29.3 \%$ in Addis Ababa [10] to 81.1\% in Dubti town, northeast Ethiopia [11]. The prevalence also varied from locality to locality within the region, and was $50.1 \%$ for Motta district [12], and 79\% for Azezo district [13] both of which are to the northwest of the Amhara Regional State, respectively. In addition to the disparities of EBF practice in different places of Ethiopia, it seems that according to reports from different authors, the country might not reach the target set to be achieved by 2019/2020 which is 93\% [14]. Understanding the factors that hinder this target point might be helpful to carry out an intervention in improving the practice.

Different studies indicated various factors that could influence EBF practices. A study conducted in Nova Scotia, Canada, showed that EBF was associated with maternal education and family income [6], but these were not the predictors for EBF practice in a study in Indonesia [15]. Maternal age was a significant factor in the study done in sub-Saharan Africa, but not so in Indonesia $[15,16]$. A study carried out in Italy indicated that antenatal care was a significant factor for EBF practice [17], but not the study done in Nigeria [18].

In Ethiopia, maternal age was not an independent predictor of EBF according to a study done in Dabat, northwest Ethiopia [19], but it was a significant factor in Debre Berhan, central Ethiopia [20]. In the study in Dabat, family income was not a significant predictor for EBF practice [19], while it was statistically associated with EBF according to a study done in Awi Zone, northwest Ethiopia [21].

As can be seen from the literature in Ethiopia, there were inconsistencies of prevalence of EBF as well as factors associated with it. This is what motivated us to conduct this study in an area where no similar study has been conducted to date.

\section{Methods \\ Study design and period}

A community based cross-sectional study was conducted to examine the prevalence and associated factors of exclusive breastfeeding practice among mothers who had infants aged between 6 and 12 months, from 1 March to 20 March 202016.

\section{Study setting and participants}

The study was conducted in Gozamin district, located $300 \mathrm{~km}$ northwest of Addis Ababa, the capital of Ethiopia. The district has 30 kebeles (lowest local administrative units). The district has a total population of 153, 151 of whom 30, 982 are women in the reproductive age group (15-49 years). There also 20,743 under-five age children and 4769 infants less than one year of age. The district has six health centers and 26 health posts that provide health services to the community [22].

\section{Sample size, sampling technique, and procedures}

The single population proportion formula was used to determine sample size, assuming a 95\% of confidence level, $5 \%$ margin of error, and $29 \%$ prevalence of exclusive breastfeeding [10]. As we have used two stage sampling, a design effect of 1.5 is considered in determining the sample size. Finally, a contingency of $10 \%$ was used to account for nonresponse during data collection. Therefore, the final sample size was estimated to be 506 mother-infant pairs.

Among the 30 kebeles in the district, seven were selected using the simple random sampling technique to achieve the primary sampling units. The total sample size was allocated to the seven kebeles proportionally, based on the number of mother-infant pairs in each kebeles received from the district health office. Sample mother-infant pairs were selected using the systematic random sampling technique with a sampling interval of three. In order to source infants eligible for the study, we moved from village to village of each selected kebeles, assessing each and every household. Out of the first three households with infants eligible for the study, the second household was selected randomly as a random start. Then, out of households with infants aged between 6 and 12 months, every three mother-infant pair were included in the sample. 


\section{Data collection and quality control}

Data were collected using interviewer administered structured questionnaire which was designed to assess EBF practice and associated factors. Each mother with an infant aged between 6 and 12 months was interviewed in order to get data regarding EBF practice and factors associated with it. The questionnaire included socioeconomic, obstetric, health, and health service related characteristics.

In order to maintain the quality of data, the questionnaire was translated from English to Amharic and back to English for consistency. Training that included field practice was given to data collectors and supervisors in kebeles which were not included in the main study. Onsite supervision was carried out by the investigators and supervisors, and feedback was given.

\section{Variables and operational definitions}

The dependent variable of the current study is exclusive breastfeeding, and an infant fed only breast milk except taking vitamins, mineral supplements, or medicines until six months [1] was included as exclusive breastfeeding. Infants who had received exclusive breastfeeding correctly were coded ' 1 ' in the SPSS during analysis, while those that had not been EBF correctly were coded ' 0 '.

The independent variables considered in this study include maternal age, marital status, maternal education, maternal occupation, monthly family income, antenatal care, breastfeeding counseling, place and mode of delivery, and HIV status of mothers.

Maternal age was categorized into four groups $(\leq 24$, $25-29,30-34$, and $\geq 35$ years), and the younger age was taken as a reference category in the logistic regression analysis. Marital status single was coded ' 0 ' and married/ union was coded as ' 1 '. Maternal education ' 1 ' was the code for mothers who were non-educated or who attended informal education and the rest were coded as ' 0 '. Housewife mothers were coded as ' 1 ' and government and private workers were encoded as ' 0 '. Family monthly income was categorized into five levels, and the lowest level was taken as a reference category. Place of delivery was categorized into three (at home, government hospital, and health center), mothers who delivered at home were coded as ' 1 ', the rest were encoded as ' 0 '. Mothers who attended antenatal care, received breastfeeding counseling services, and had breastfeeding experience were coded as ' 1 ' and their respective counterparts were coded as ' 0 '. Mothers with Human Immunodeficiency Virus (HIV) positive mothers were coded as ' 0 ' and HIV negative mothers as ' 1 '. A health post is the lowest health facility structure in Ethiopian health tier system.

\section{Statistical analysis}

Data were entered, coded and cleaned, using Epi-info version 7.0 statistical software and then transferred to SPSS software version 20 for further data processing and analysis. Text descriptions, tables, charts, and graphs were used to describe the relevant findings of the study.

The Crude Odds Ratios (COR) with a 95\% confidence interval (CI) were estimated in the binary logistic regression analysis to assess the association between each independent variable and the outcome variable, and to select candidate variables for the multivariate logistic regression analysis. Because there were relatively a large number of independent variables considered in this study, we had to screen them using the bivariate logistic regression to minimize the chance of multicollinearity in the multivariate logistic regression. Thus, only those independent variables with a $p$ - values of 0.20 or less in the bivariate logistic regression were included in the multivariate logistic regression to get the adjusted effect of each covariate [23].

Adjusted Odds Ratio with a 95\% confidence interval were estimated to assess the strength of the association. Variables with $p$ - value less than 0.05 in the multivariate logistic regression analysis were considered as significant and independent predictors of exclusive breastfeeding practice.

\section{Results}

\section{Sociodemographic characteristics}

Out of a total of 506 eligible mother-infant pairs, 478 participated in this study with a response rate of $94.4 \%$.The mean age of mothers was $28.62 \pm 4.95$ SD years. Four hundred twenty-five mothers $(88.1 \%)$ were married, 461 (96.4\%) were Orthodox Christians, and 472 (98.7\%) were Amhara in ethnicity. More than half (51.9\%) of the mothers were housewives and 141 (29.5\%) completed secondary school (Table 1).

\section{Maternal and infant health service utilizations}

Of all the study participants, 450 (94.1\%) of the mothers attended antenatal care during pregnancy. Out those who had antenatal care, 333 (69.7\%) mothers received breastfeeding counseling. Four hundred thirty eight (91.6\%) mothers had their infants with vaginal mode of delivery (Table 2).

\section{Exclusive breastfeeding by other characteristics}

Among all mothers who participated in the study, nearly three-fourths $(74.1 \%)$ breastfed their infants exclusively during the first six months of age (95\% CI 70.8, 79.1). In this study, among mothers who had male infants, $73 \%$ practiced exclusive breastfeeding, while $77.2 \%$ of the mothers who had female infants did so. Similarly, among mothers who were attended by health professionals during delivery, $78.4 \%$ practiced EBF while only $43.8 \%$ of the mothers attended by relatives or friends breastfed their infants exclusively (Table 3). 
Table 1 Sociodemographic characteristics of mothers in Gozamin district, northwest Ethiopia $(n=478)$

\begin{tabular}{|c|c|c|}
\hline Characteristics & Number & Percent \\
\hline \multicolumn{3}{|l|}{ Ethnicity of mother } \\
\hline \multicolumn{3}{|l|}{ Amhara } \\
\hline Tigray & 472 & 98.7 \\
\hline SNNP & 4 & 0.8 \\
\hline Religion of mother & 2 & 0.5 \\
\hline Orthodox & 461 & 96.4 \\
\hline Muslim & 7 & 1.5 \\
\hline Protestant & 10 & 2.0 \\
\hline \multicolumn{3}{|l|}{ Sex of infant } \\
\hline Male & 259 & 54.2 \\
\hline Female & 219 & 45.8 \\
\hline \multicolumn{3}{|l|}{ Maternal age (in years) } \\
\hline$\leq 24$ & 88 & 18.4 \\
\hline $25-29$ & 198 & 41.4 \\
\hline $30-34$ & 128 & 26.8 \\
\hline$\geq 35$ & 64 & 13.4 \\
\hline \multicolumn{3}{|l|}{ Marital status } \\
\hline Married & 425 & 88.1 \\
\hline Divorced & 13 & 2.7 \\
\hline Widowed & 44 & 9.2 \\
\hline \multicolumn{3}{|l|}{ Number of children } \\
\hline$\leq 3$ & 414 & 86.6 \\
\hline$>3$ & 64 & 13.4 \\
\hline \multicolumn{3}{|l|}{ Maternal education } \\
\hline Informal and not educated & 91 & 19.0 \\
\hline Primary & 89 & 18.6 \\
\hline Secondary & 141 & 29.5 \\
\hline Certificate, and above & 157 & 32.8 \\
\hline \multicolumn{3}{|l|}{ Educational status of husband } \\
\hline Informal and none educated & 88 & 18.4 \\
\hline Primary & 70 & 14.6 \\
\hline Secondary & 115 & 24.1 \\
\hline Certificate and above & 205 & 42.9 \\
\hline \multicolumn{3}{|l|}{ Maternal occupation } \\
\hline House wife & 248 & 51.9 \\
\hline Government employee & 106 & 22.2 \\
\hline Private employee & 113 & 23.6 \\
\hline Private organization employee & 11 & 2.3 \\
\hline \multicolumn{3}{|l|}{ Family monthly income (ETB) } \\
\hline$\leq 650$ & 76 & 15.9 \\
\hline $651-1400$ & 87 & 18.2 \\
\hline $1401-2350$ & 103 & 21.5 \\
\hline $2351-3550$ & 81 & 16.9 \\
\hline$\geq 3551$ & 131 & 27.4 \\
\hline
\end{tabular}

ETB Ethiopian Birr
Table 2 Health and health service characteristics of mothers in Gozamin district, northwest Ethiopia $(n=478)$

\begin{tabular}{|c|c|c|}
\hline Characteristics & Number & Percent \\
\hline \multicolumn{3}{|l|}{ Antenatal care } \\
\hline Yes & 450 & 94.1 \\
\hline No & 28 & 5.9 \\
\hline \multicolumn{3}{|c|}{ Breastfeeding counseling during pregnancy } \\
\hline Yes & 333 & 69.7 \\
\hline No & 145 & 30.3 \\
\hline \multicolumn{3}{|l|}{ Place of birth/delivery } \\
\hline At home & 53 & 11.1 \\
\hline Government hospital & 321 & 67.1 \\
\hline Government health center, post & 104 & 21.8 \\
\hline \multicolumn{3}{|l|}{ Mode of delivery } \\
\hline Vaginal & 438 & 91.6 \\
\hline Cesarean section & 40 & 8.4 \\
\hline \multicolumn{3}{|l|}{ Attendant of the delivery } \\
\hline Health profession & 430 & 90.0 \\
\hline Relative/friends & 48 & 10.0 \\
\hline \multicolumn{3}{|l|}{ Breastfeeding counseling after delivery } \\
\hline Yes & 365 & 76.4 \\
\hline No & 113 & 23.6 \\
\hline \multicolumn{3}{|l|}{ Breastfeeding experience } \\
\hline Yes & 273 & 57.1 \\
\hline No & 205 & 42.9 \\
\hline \multicolumn{3}{|l|}{ Maternal HIV status } \\
\hline Positive & 27 & 5.6 \\
\hline Negative & 451 & 94.4 \\
\hline
\end{tabular}

Factors associated with exclusive breastfeeding

In the bivariate logistic regression, sex, marital status, educational status, HIV status of the mothers, and counseling about breastfeeding during antenatal care were not found to have statistically significant association with EBF at $p$ - value of 0.2. However, variables including maternal age, family monthly income, occupation of the mother, place of delivery, counseling about breastfeeding after delivery, and five other variables were included in the multivariable logistic regression model.

When each independent variable was adjusted for other variables, occupation of mother, place of delivery, and counseling about breastfeeding after delivery were found to be statistically significantly associated with exclusive breastfeeding at a 95\% confidence level and a $p$ - value of 0.05 .

Government employed mothers reduced the odds of EBF practice almost by $50 \%$ (AOR $0.49,95 \%$ CI $0.26,0.94$ ) compared to housewives. Similarly, mothers who did not receive counseling about breastfeeding after delivery reduced the odds of EBF by $57.4 \%$ compared to their non- 
Table 3 Exclusive breastfeeding by different factors for mothers in Gozamin district, northwest Ethiopia $(n=478)$

\begin{tabular}{lll}
\hline Characteristics & \multicolumn{2}{l}{ Exclusive breastfeeding } \\
\cline { 2 - 3 } & Number & Percent \\
\hline Exclusive breastfeeding & 355 & 74.1 \\
Yes & 123 & 25.9 \\
No & & \\
Sex of infant & 189 & 73 \\
Male & 169 & 77.2 \\
Female & & \\
Delivery attendant & 377 & 78.4 \\
Health professional & 21 & 43.8 \\
Relative/friend & & \\
Birth interval & 157 & 81.8 \\
First pregnancy & 31 & 75.6 \\
$27-38$ months & 170 & 69.4 \\
Z39 months & & 76.6 \\
Number of children & 317 & 64.1 \\
$1-3$ & 41 & \\
$\geq 4$ & & \\
\hline
\end{tabular}

counseled counterparts (AOR 0.43, 95\% CI 0.25, 0.72). The odds of EBF for mothers who delivered at the government hospital was two-fold (AOR 2.01, 95\% CI 1.02, 3.94) compared to mothers who delivered at home (Table 4).

\section{Discussion}

This study has attempted to assess the magnitude of exclusive breastfeeding practice and associated factors during the first six months of infant life among mother-infant pairs in Gozamin district, northwest Ethiopia. The prevalence of EBF was $74.1 \%$. This finding was greater than that of a study conducted in Dabat district, northwest Ethiopia, whose prevalence of EBF was 30.7\% [24]. It was also higher than the national level prevalence of $52 \%$ reported by Ethiopian Demographic and Health Survey (EDHS) in 2011 [22]. This difference could be the result of efforts and multi-sectoral collaborations that have been made by the Government of Ethiopia on child nutrition since 2013 [14], while the studies mentioned above used data collected before the implementation of these revised national nutrition programs. In addition, the national study included samples from the less developed and pastoral regions with less health service coverage, which might have resulted in less awareness about exclusive breastfeeding.

Regarding factors that could affect EBF, occupation of the mother, place of delivery, and breastfeeding counseling after delivery were statistically significantly associated with EBF practice. Accordingly, government employed mothers were less likely to practice EBF compared to housewife mothers. This finding is in line with those of studies done in the rural communities of northwest Ethiopia [24], eastern region of Ghana [25], Kinshasa [7], and Saudi Arabia [26]. Perhaps this is because employed mothers have no time to exclusively breastfeed their infants, or they have short maternity leave to stay with and establish breastfeeding their newborn babies, or they lack convenient locations to breastfeed at their working places. On the contrary, a study done in Bangladesh showed that mothers working outside their houses were more likely to practice exclusive breastfeeding. The possible explanation for this difference might be that in Bangladesh most women take their babies to their work places [27].

In this study, mothers who delivered at health institutions were more likely to practice exclusive breastfeeding compared to mothers who delivered at home. These findings were similar to a study done at Dabat Health and Demographic Surveillance System site in northwest Ethiopia [24] and Ghana [28]. This might be so because mothers who gave birth at health institutions could have more chance to receive obstetric and postnatal care, nutritional education and counseling on the benefits of breastfeeding, correct positioning, and attachment.

Exclusive breastfeeding in this study is significantly associated with breastfeeding counseling after delivery. This result is supported studies done in Debre Berhan district, central Ethiopia [20], Addis Ababa public health centers, Ethiopia [10], and Kilimanjaro Region, northern Tanzania [29]. One possible explanation for the observed association could be that breastfeeding counseling after delivery might have helped mothers to improve their maternal knowledge regarding exclusive breastfeeding.

In our study, antenatal care visits were not significantly associated with EBF practice. However, in studies conducted in Dabat, northwest Ethiopia [24], among urban women at Addis Ababa public health centers, Ethiopia [10], and Timor-Leste [8] indicated that mothers who had antenatal care visits had a better practice of exclusive breastfeeding. The possible reason for this difference might be that in this study mothers who attended antenatal care did not receive breastfeeding counseling.

\section{Limitations of the study}

In our study, the age of the infants in the mother-infant pairs was between 6 and 2 months. This period could be assumed to be long enough to result in a recall bias of either over or underestimating the finding of the work.

\section{Conclusion}

The incidence of exclusive breastfeeding in this work was relatively high compared to other previous studies. A mothers' occupation, giving birth at health facilities, and the provision of counseling about breastfeeding after delivery were significantly associated with EBF practice. Therefore, 
Table 4 Bivariate and multivariate logistic regression analysis of exclusive breastfeeding among mothers in Gozamin district, northwest Ethiopia $(n=478)$

\begin{tabular}{|c|c|c|c|c|}
\hline \multirow[t]{2}{*}{ Variables } & \multicolumn{2}{|c|}{ Exclusive breastfeeding } & \multirow{2}{*}{$\begin{array}{l}\text { Crude Odds } \\
\text { Ratio }(95 \% \mathrm{Cl})\end{array}$} & \multirow{2}{*}{$\begin{array}{l}\text { Adjusted Odds } \\
\text { Ratio }(95 \% \mathrm{Cl})\end{array}$} \\
\hline & \multicolumn{2}{|c|}{ Yes (\%) No (\%) } & & \\
\hline \multicolumn{5}{|l|}{ Maternal age (in years) } \\
\hline$\leq 24$ & $72(81.8)$ & $16(18.2)$ & 1 & 1 \\
\hline $25-29$ & $155(78.3)$ & $43(21.7)$ & $0.80(0.42,1.52)$ & $0.87(0.44,1.73)$ \\
\hline $30-34$ & $88(68.8)$ & $40(31.2)$ & $0.49(0.25,0.94)$ & $0.52(0.26,1.06)$ \\
\hline$\geq 35$ & $43(67.2)$ & $21(32.8)$ & $0.46(0.21,0.97)$ & $0.57(0.25,1.27)$ \\
\hline \multicolumn{5}{|l|}{ Marital status } \\
\hline Married/in union & $317(75.3)$ & $104(24.7)$ & 1 & 1 \\
\hline Single & $41(71.9)$ & $16(28.1)$ & $0.84(0.45,1.56)$ & $0.81(0.38,1.74)$ \\
\hline \multicolumn{5}{|l|}{ Maternal education } \\
\hline No education \& Informal & $62(68.1)$ & 29 (31.9) & 1 & 1 \\
\hline Primary education & $70(78.7)$ & $19(21.3)$ & $1.72(0.88,3.37)$ & $1.41(0.65,3.05)$ \\
\hline Secondary education & $110(78.0)$ & $31(22.0)$ & $1.66(0.92,3.01)$ & $0.93(0.45,1.91)$ \\
\hline Certificate and above & $116(73.9)$ & $41(26.1)$ & $1.29(0.73,2.27)$ & $0.76(0.33,1.77)$ \\
\hline \multicolumn{5}{|l|}{ Husband' education } \\
\hline Informal education & $59(67.0)$ & $29(33.0)$ & 1 & 1 \\
\hline Primary education & $56(80.0)$ & $14(20.0)$ & $1.97(0.94,4.10)$ & $1.55(0.64,3.77)$ \\
\hline Secondary education & $91(79.1)$ & $24(20.9)$ & $1.86(0.9,3.01)$ & $1.23(0.50,3.02)$ \\
\hline Certificate and above & $152(74.1)$ & $53(25.9)$ & $1.32(0.75,2.33)$ & $1.02(0.41,2.56)$ \\
\hline \multicolumn{5}{|l|}{ Maternal occupation } \\
\hline House wife & $180(72.6)$ & $68(27.4)$ & 1 & 1 \\
\hline Government employee & $75(70.8)$ & $31(29.2)$ & $0.91(0.55,1.51)$ & $0.49(0.26,0.94)^{*}$ \\
\hline Private work & $103(83.1)$ & $21(16.9)$ & $1.85(1.07,3.20)$ & $1.69(0.95,2.99)$ \\
\hline \multicolumn{5}{|l|}{ Monthly family income (in Birr) } \\
\hline$\leq 650$ & $53(69.7)$ & $23(30.3)$ & 1 & 1 \\
\hline $651-1400$ & $60(69.0)$ & $27(31.0)$ & $0.96(0.49,1.90)$ & $0.91(0.44,1.86)$ \\
\hline $1401-2350$ & $83(70.6)$ & $20(19.4)$ & $1.80(0.90,3.59)$ & $1.93(0.92,4.03)$ \\
\hline $2351-3550$ & $60(74.1)$ & $21(25.9)$ & $1.24(0.62,2.49)$ & $1.22(0.57,2.58)$ \\
\hline$\geq 3551$ & $102(77.9)$ & $29(22.1)$ & $1.53(0.80,2.89)$ & $2.15(0.98,4.72)$ \\
\hline \multicolumn{5}{|l|}{ Antenatal care } \\
\hline Yes & $341(74.8)$ & $109(24.2)$ & 1 & 1 \\
\hline No & $17(60.7)$ & $11(39.3)$ & $0.49(0.23,1.09)$ & $0.65(0.27,1.56)$ \\
\hline \multicolumn{5}{|l|}{ BF counseling during ANC } \\
\hline Yes & $253(76.0)$ & $80(24.0)$ & 1 & 1 \\
\hline No & $105(72.4)$ & $40(27.6)$ & $0.83(0.53,1.29)$ & $0.90(0.52,1.55)$ \\
\hline \multicolumn{5}{|l|}{ Place of delivery } \\
\hline Home & $26(49.1)$ & $27(50.9)$ & 1 & 1 \\
\hline Government hospital & $243(75.7)$ & $78(24.3)$ & $3.23(1.78,5.87)$ & $2.01(1.02,3.94)^{*}$ \\
\hline Health center, post & 89 (85.6) & $15(14.4)$ & $6.16(2.86,13-28)$ & $4.56(2.01,10.37)^{*}$ \\
\hline \multicolumn{5}{|l|}{ Mode of delivery } \\
\hline Cesarean section & $34(85.0)$ & $6(15.0)$ & $1.99(0.82,4.87)$ & $2.02(0.79,5.16)$ \\
\hline Vaginal & $324(74.0)$ & $114(26.0)$ & 1 & 1 \\
\hline
\end{tabular}


Table 4 Bivariate and multivariate logistic regression analysis of exclusive breastfeeding among mothers in Gozamin district, northwest Ethiopia $(n=478)$ (Continued)

\begin{tabular}{|c|c|c|c|c|}
\hline \multicolumn{5}{|c|}{ BF counseling after delivery } \\
\hline Yes & $290(79.5)$ & $75(20.5)$ & 1 & \\
\hline No & $68(60.2)$ & $45(39.8)$ & $0.39(0.25,0.60)$ & $0.43(0.25,0.72)^{*}$ \\
\hline \multicolumn{5}{|c|}{ Maternal HIV status } \\
\hline Positive & $21(77.8)$ & $6(22.2)$ & $1.18(0.47,3.01)$ & $1.08(0.37,3.14)$ \\
\hline Negative & $337(74.7)$ & $114(25.3)$ & 1 & 1 \\
\hline \multicolumn{5}{|c|}{ Breastfeeding experience } \\
\hline Yes & $194(71.1)$ & $79(28.9)$ & 1 & 1 \\
\hline No & $164(80.0)$ & $41(20.0)$ & $1.63(1.06,2.51)$ & $1.26(0.76,2.09)$ \\
\hline
\end{tabular}

*Significant at $p$ - value of $\leq 0.05, \mathrm{BF}$ - breastfeeding, ANC- antenatal care

we suggest that health institutions encourage hospital birthing and increase breastfeeding counseling after delivery. Employers need to consider giving longer maternity leave to improve exclusive breastfeeding practice.

\section{Abbreviations}

AOR: Adjusted Odd Ratio; BF: Breastfeeding; COR: Crude Odd Ratio; EBF: Exclusive Breastfeeding; EDHS: Ethiopian Demographic and Health Survey; ETB: Ethiopian Birr; NGO: Non Governmental Organizations; UNICEF: United Nations Children's Fund; WHO: World Health Organization

\section{Acknowledgements}

Authors would like to thank University of Gondar for approving ethical clearance. We would like also to thank data collectors, supervisors and study participants.

\section{Funding}

The authors declare that there is no funding source.

\section{Availability of data and materials}

Full data set and materials pertaining to this study can be obtained from corresponding author on reasonable request.

\section{Authors' contributions}

MTH concepted the study, developed the proposal and supervised field work and made the analysis. LDG worked on the interpretation or discussion of results. AST assisted in the conception of the study, involved in the method development, analysis, interpretation of the findings and in developing the manuscript. All the authors read, revised and approved the final manuscript

\section{Ethics approval and consent to participate}

Ethical clearance was obtained from the Ethical Review Board (IRB) of the University of Gondar. A letter of permission was obtained from the Amhara Regional State Health Bureau, East Gojjam Zone Health Department, Gozamin District Health Office, and all kebele administrations. The participants were informed about the objectives, expected outcomes, benefits and the risks associated with the study. Verbal consent was obtained from the mothers before the interview. Confidentiality of responses was maintained throughout the study. The data collectors counseled mothers about the significance of exclusive breastfeeding after data were collected.

\section{Consent for publication}

Not applicable.

\section{Competing interests}

The authors declare that they have no competing interests.

\section{Author details}

${ }^{1}$ Department of Human Nutrition, College of Medicine and Health Science, University of Gondar, P.O Box, 196 Gondar, Ethiopia. ${ }^{2}$ Department of Epidemiology and Biostatistics, Institute of Public Health, College of Medicine and Health Sciences, University of Gondar, P.O Box, 196 Gondar, Ethiopia.

Received: 26 January 2017 Accepted: 25 June 2017

Published online: 10 July 2017

\section{References}

1. WHO/UNICEF. Acceptable medical reasons for use of breast-milk substitutes. http://www.nationalplanningcycles.org/sites/default/files/planning_cycle_ repository/lao_peoples_democratic_republic/final_lao_version_nnspa_ 2016_matrix_updated_21_dec_2015_-_part_1_rta_-.pdf\%0B.

2. Ministry of Health in Ethiopia. Government of the Federal Democratic Republic of Ethiopia National Nutrition Programme; 2013. https://www. unicef.org/ethiopia/National_Nutrition_Programme.pdf.

3. Victora CG, Bahl R, Barros AJ, França GV, Horton S, Krasevec J, et al. Breastfeeding in the 21st century: epidemiology, mechanisms, and lifelong effect. Lancet. 2016;387(10017):475-90.

4. Maonga AR, Mahande MJ, Damian DJ, Msuya SE. Factors affecting exclusive breastfeeding among women in Muheza District Tanga northeastern Tanzania: a mixed method community based study. Matern Child Health J. 2016:20:77-87.

5. Greenwood B. A global action plan for the prevention and control of pneumonia. Bull World Health Organ. 2008;86(5):322.

6. Brown CR, Dodds L, Attenborough R, Bryanton J, Rose AE, Flowerdew G, et al. Rates and determinants of exclusive breastfeeding in first 6 months among women in Nova Scotia: a population-based cohort study. CMAJ Open. 2013;1(1):E9-17.

7. Babakazo P, Donnen P, Akilimali P, Ali NM, Okitolonda E. Predictors of discontinuing exclusive breastfeeding before six months among mothers in Kinshasa: a prospective study. Int Breastfeed J. 2015;10:19.

8. Khanal V, da Cruz JLNB, Karkee R, Lee AH. Factors associated with exclusive breastfeeding in Timor-Leste: findings from Demographic and health Survey 2009-2010. Nutrients. 2014;6(4):1691-700.

9. Kim MJ, Kim Y-M, Yoo J-H. Factors affecting exclusive breast-feeding during the first 6 months in Korea. J Jpn Pediatr Soc. 2013;55(2):177-80.

10. Shifraw T, Worku A, Berhane Y. Factors associated exclusive breastfeeding practices of urban women in Addis Ababa public health centers. Ethiopia: a cross sectional study Int Breastfeed J. 2015;10:22.

11. Liben ML, Gemechu YB, Adugnew M, Asrade A, Adamie B, Gebremedin E, et al. Factors associated with exclusive breastfeeding practices among mothers in dubti town, afar regional state, northeast Ethiopia: a community based cross-sectional study. Int Breastfeed J. 2016;11:4.

12. Tewabe T, Mandesh A, Gualu T, Alem G, Mekuria G, Zeleke H. Exclusive breastfeeding practice and associated factors among mothers in Motta town, east Gojjam zone, Amhara regional state, Ethiopia, 2015: a crosssectional study. Int Breastfeed J. 2016;12:12.

13. Asemahagn MA. Determinants of exclusive breastfeeding practices among mothers in azezo district, northwest Ethiopia. Int Breastfeed J. 2016;11:22. 
14. National Nutrition Program From 2016-2020; Edited in http://www. nationalplanningcycles.org/sites/default/files/planning_cycle_repository/lao_ peoples_democratic_republic/final_lao_version_nnspa_2016_matrix_ updated_21_dec_2015 - part_1_rta_-pdf.

15. Paramashanti BA, Hadi H, Gunawan IM. Timely initiation of breastfeeding is associated with the practice of exclusive breastfeeding in Indonesia. Asia Pac J Clin Nutr 2016;25S(1):S52-56.

16. Yalçin SS, Berde AS, Yalçin S. Determinants of exclusive breast feeding in sub-Saharan Africa: a multilevel approach. Paediatr Perinat Epidemiol. 2016; 30(5):439-49.

17. Lauria L, Spinelli A, Grandolfo M. Prevalence of breastfeeding in Italy: a population based follow-up study. Ann Ist Super Sanita. 2016;52(3):457-61.

18. Gayawan $\mathrm{E}$, Adebayo SB, Chitekwe $\mathrm{S}$. Exclusive breastfeeding practice in Nigeria: a Bayesian stepwise regression analysis. Matern Child Health J. 2014; 18(9):2148-57.

19. Biks GA, Berhane Y, Worku A, Gete YK. Exclusive breast feeding is the strongest predictor of infant survival in Northwest Ethiopia: a longitudinal study. J Health Popul Nutr. 2015;34:9.

20. Asfaw MM, Argaw MD, Kefene ZK. Factors associated with exclusive breastfeeding practices in Debre Berhan District Central Ethiopia: a cross sectional community based study. Int Breastfeed J. 2015;10:23.

21. Yeneabat T, Belachew T, Haile M. Determinants of cessation of exclusive breastfeeding in Ankesha Guagusa Woreda, Awi zone Northwest Ethiopia: a cross-sectional study. BMC Pregnancy Childbirth. 2014;14:262.

22. Central Statistical Agency [Ethiopia] all. Ethiopia Demographic and Health Survey 2011. Addis Ababa, Ethiopia and Calverton. Maryland, USA: Central Statistical Agency and ORC Macro; 2012.

23. Hosmer DW, Lemeshow S. Model-building strategies and methods for logistic regression. In: Applied Logistic Regression. John Wiley \& Sons, Inc. $2^{\text {nd }}$ edition; 2000. p. 91-142.

24. Biks GA, Tariku A, Tessema GA. Effects of antenatal care and institutional delivery on exclusive breastfeeding practice in northwest Ethiopia: a nested case-control study. Int Breastfeed J. 2015:10:30

25. Otoo GE, Lartey AA, Pérez-Escamilla R. Perceived incentives and barriers to exclusive breastfeeding among periurban Ghanaian women. J Hum Lact. 2009;25(1):34-41.

26. El-Gilany A-H, Shady E, Helal R. Exclusive breastfeeding in al-Hassa. Saudi Arabia Breastfeed Med. 2011;6(4):209-13.

27. Akter S, Rahman MM. The determinants of early cessation of breastfeeding in Bangladesh. World Health Popul. 2009;11(4):5-12.

28. Tampah-Naah AM, Kumi-Kyereme A. Determinants of exclusive breastfeeding among mothers in Ghana: a cross-sectional study. Int Breastfeed J. 2013;8:13.

29. Mgongo M, Mosha MV, Uriyo JG, Msuya SE, Stray-Pedersen B. Prevalence and predictors of exclusive breastfeeding among women in Kilimanjaro region Northern Tanzania a population based cross-sectional study. Int Breastfeed J. 2013;8:12

\section{Submit your next manuscript to BioMed Central and we will help you at every step:}

- We accept pre-submission inquiries

- Our selector tool helps you to find the most relevant journal

- We provide round the clock customer support

- Convenient online submission

- Thorough peer review

- Inclusion in PubMed and all major indexing services

- Maximum visibility for your research

Submit your manuscript at www.biomedcentral.com/submit

CBiomed Central 